\title{
Trigoniaceae endémicas del Perú
}

\section{Blanca León ${ }^{1,2}$}

${ }^{1}$ Museo de Historia Natural, Av. Arenales 1256, Aptdo. 14-0434, Lima 14, Perú

2 Plant Resources Center, University of Texas at Austin, Austin TX 78712 EE.UU.

blanca.leon@mail.utexas.edu

\section{Resumen}

La familia Trigoniaceae es reconocida en el Perú por presentar un género, Trigonia, y seis especies (Brako \& Zarucchi, 1993), entre arbustos, lianas y árboles. En este trabajo reconocemos una especie endémica, la cual ha sido encontrada en la región Bosques Húmedos Amazónicos, a $100 \mathrm{~m}$ de altitud. No ha sido registrada dentro del Sistema Nacional de Áreas Naturales Protegidas por el Estado.

Palabras claves: Trigoniaceae, Trigonia, Perú, endemismo, plantas endémicas.

\section{Abstract}

The Trigoniaceae are represented in Peru by one genus, Trigonia, and six species (Brako \& Zarucchi, 1993), between trees, lianas and shrubs. Here we recognize one endemic species, which is found in Humid Lowland Amazonian Forests region, to $100 \mathrm{~m}$ elevation. It has not been recorded within Peru's protected areas system.

Keywords: Trigoniaceae, Trigonia, Peru, endemism, endemic plants.

\section{Trigonia macrantha Warm.}

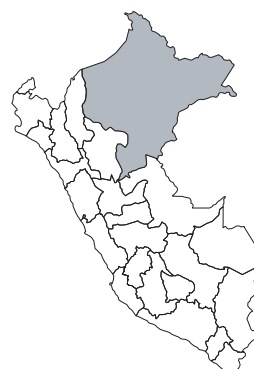

\section{DD}

Publicación: Fl. Bras. 13(2): 129. 1875.

Colección tipo: R. Spruce 3871

Herbarios: BR, CGE, G, NY, OXF, W.

Nombre común: Desconocido.

Registro departamental: LO.

Regiones Ecológicas: BHA; $100 \mathrm{~m}$.

SINANPE: Sin registro.

Herbarios peruanos: Ninguno.

Observaciones: Esta especie arbustiva, se conoce solamente de la cuenca baja del río Huallaga, de bosques en los alrededores de Yurimaguas. Podría estar representada en la flora ecuatoriana. Se desconoce el estado de sus poblaciones. 